Geopolítica(s) Revista de estudios sobre espacio y poder ISSN: 2172-3958

https://dx.doi.org/10.5209/geop.70908

\title{
Índice de vulnerabilidad y trayectorias espaciales del COVID-19 en el Distrito Metropolitano de Quito
}

\author{
Augusto Barrera ${ }^{1}$, Alejandra Bonilla ${ }^{2}$, Salomé Espinosa $^{3}$, Javier González ${ }^{4}$, Caridad \\ Santelices $^{5}$ y Johanna Villavicencio ${ }^{6}$
}

Recibido: 29 de julio de 2020 / Aceptado: 22 de diciembre de 2020

Resumen. Este trabajo analiza la trayectoria espacial de los contagios del COVID-19 en el Distrito Metropolitano de Quito (DMQ) durante el periodo definido como aislamiento social (el período de confinamiento social denominado "semáforo rojo" tuvo lugar en Quito desde 9 de abril al 3 de junio de 2020). El objetivo principal es identificar las principales tendencias de expansión del contagio y correlacionarlas con las dimensiones de la vida urbana. La investigación analiza los contagios en el área urbana funcional de Quito; esto es, el núcleo urbano consolidado y las parroquias rurales conurbadas con las que hay continuidad en la disposición del amanzanamiento. La investigación desarrolla un índice de vulnerabilidad a partir de dimensiones demográficas, socioeconómicas y del hábitat, para correlacionar las parroquias más vulnerables con la evolución de contagios del COVID-19. Por tanto, se trata de un estudio exploratorio que, con evidencia empírica puesta a disposición por los organismos oficiales, muestra los patrones socioespaciales de la pandemia y su correlación con los grados de vulnerabilidad en un lugar concreto. Finalmente, en base a los resultados obtenidos se plantea una discusión para la formulación de políticas que mitiguen el impacto social del COVID-19.

Palabras clave: COVID-19; Ecuador; evolución pandemia; patrones espaciales, vulnerabilidad.

1 Facultad Latinoamericana de Ciencias Sociales (FLACSO) Ecuador.

Email: abarrera@flacso.edu.ec

https://orcid.org/0000-0001-5522-0770

2 Facultad Latinoamericana de Ciencias Sociales (FLACSO) Ecuador.

Email: apbonillam@gmail.com

https://orcid.org/0000-0001-7054-0481

3 Facultad Latinoamericana de Ciencias Sociales (FLACSO) Ecuador.

Email: ivonne.espinosa@udla.edu.ec

https://orcid.org/0000-0002-6470-0298

4 Facultad Latinoamericana de Ciencias Sociales (FLACSO) Ecuador.

Email: fjgcomin@gmail.com

https://orcid.org/0000-0002-7358-0013

5 Facultad Latinoamericana de Ciencias Sociales (FLACSO) Ecuador. Email: mcaridadsantelices@gmail.com https://orcid.org/0000-0002-6926-2960

6 Facultad Latinoamericana de Ciencias Sociales (FLACSO) Ecuador. Email: johannavillavicencio86@gmail.com

https://orcid.org/0000-0002-0033-7282 


\title{
[en] Vulnerability Index and Spatial Trajectories of COVID-19 in the Metropolitan District of Quito
}

\begin{abstract}
This work analyzes the spatial trajectory of COVID-19 infections in the Metropolitan District of Quito (DMQ) during the period defined as social isolation (the period of social confinement called "red traffic light" took place in Quito from April 9 as of June 3,2020). The main objective is to identify the main trends in the spread of contagion and correlate them with the dimensions of urban life. The research analyses the contagions in the functional urban area of Quito, that is, the consolidated urban nucleus and the conurbed rural parishes with which there is continuity in the provision of amanzanamiento. The research develops a vulnerability index based on demographic, socioeconomic and habitat dimensions, to correlate the most vulnerable parishes with the evolution of COVID-19 infections. Therefore, it is an exploratory study that, with empirical evidence made available by official organizations, shows the socio-spatial patterns of the pandemic and its correlation with the degrees of vulnerability in a specific place. Finally, based on the results obtained, a discussion is proposed for the formulation of policies that mitigate the social impact of COVID-19.
\end{abstract}

Keywords: COVID-19; Ecuador; pandemic evolution; spatial patterns, vulnerability.

\section{[pt] Índice de vulnerabilidade e trajetórias espaciais do COVID-19 no Distrito Metropolitano de Quito}

Resumo. Este trabalho analisa a trajetória espacial das infecções por COVID-19 no Distrito Metropolitano de Quito (DMQ) durante o período definido como isolamento social (o período de confinamento denominado "semáforo vermelho" ocorreu em Quito de 9 de abril a 3 de junho de 2020). O objetivo principal é identificar as principais tendências de propagação do contágio e correlacioná-las com as dimensões da vida urbana. A pesquisa analisa o contágio na área urbana funcional de Quito, ou seja, o núcleo urbano consolidado e as freguesias rurais conurbadas com as quais existe continuidade urbanística. A pesquisa desenvolve um índice de vulnerabilidade com base nas dimensões demográficas, socioeconômicas e do hábitat, buscando correlacionar as freguesias mais vulneráveis com a evolução das infecções por COVID-19. Portanto, é um estudo exploratório que, com evidências empíricas disponibilizadas por órgãos oficiais, mostra os padrões socioespaciais da pandemia e sua correlação com os graus de vulnerabilidade em um determinado local. Por fim, com base nos resultados obtidos, propõese uma discussão para a formulação de políticas que mitiguem o impacto social do COVID-19.

Palavras-chave: COVID-19; Equador; evolução pandêmica; padrões espaciais, vulnerabilidade.

Sumario. Introducción. 1. Marco teórico. 1.1. Geografía, desigualdad y vulnerabilidad en el contexto del COVID-19. 1.2. Determinantes sociales y dimensiones de análisis. 2. Caso de estudio. 3. Metodología. 4. Resultados. 4.1. Análisis de la evolución de los contagios en el DMQ. 4.2. Tendencias de distribución espacial. 4.3. Resultados de las dimensiones del índice. 4.4. Resultados del Índice de Vulnerabilidad. Discusión y reflexiones finales. Referencias.

Cómo citar: Barrera, A., Bonilla, A., Espinosa, S., González, J., Santelices, C. y Villavicencio, J. (2021). Índice de vulnerabilidad y trayectorias espaciales del COVID-19 en el Distrito Metropolitano de Quito. Geopolítica(s). Revista de estudios sobre espacio y poder, 12(1), 51-76. https://dx.doi.org/10.5209/geop.70908 


\section{Introducción}

La COVID-197 ${ }^{7}$ que apareció inicialmente en la ciudad china de Wuhan, se ha propagado a todo el mundo y ha tenido como escenario principal a las ciudades. La ahora pandemia impactó, desde aproximadamente marzo de 2020, a prácticamente todas las ciudades y metrópolis de América Latina. Por un lado, parece evidente que el efecto de aglomeración urbana facilita la expansión del contagio del virus. Sin embargo, en ningún caso se puede afirmar que la densidad es el elemento único o determinante de las trayectorias y patrones espaciales de los contagios, pues éstos no evolucionan de manera homogénea en todas las ciudades, al contrario, los contagios se distribuyen adoptando patrones específicos en cada lugar.

El mecanismo de contagio de la COVID-19 ocurre principalmente en distancias cortas, por contacto y gotas respiratorias. Hasta el momento no se puede descartar completamente que exista cierto grado de transmisión por vía aérea, y parece existir un mayor riesgo cuando se trata de un contacto prolongado y en espacios cerrados o con una ventilación deficiente. Además, los altos niveles de contagios se explican también por la posibilidad de que los pacientes sean asintomáticos, lo cual dificulta el control y seguimiento del contagio (Santos, Siqueira, Praça y Albuquerque, 2020).

Todos estos factores indican la necesidad de establecer cierto grado de asociación espacial entre la evolución de los casos de contagio de la COVID-19 con un conjunto de factores propios de la configuración espacial de las ciudades (por ejemplo, la aglomeración urbana). Adicionalmente, existen otros factores socioeconómicos propios de la vida urbana, cuya cotidianeidad se ha visto profundamente alterada en todas las latitudes del mundo por la aparición de la pandemia. Esta nueva realidad, a escala tanto global como local, está mostrando las debilidades de un modelo urbano y social cuyas aristas dan luz a nuevas y viejas desigualdades. En este sentido, desde un enfoque geoespacial esta investigación pretende demostrar el conjunto de correlaciones espaciales que hay entre la concentración de los casos de contagio con las condiciones de vulnerabilidad social.

\section{Marco teórico}

\subsection{Geografía, desigualdad y vulnerabilidad en el contexto del COVID-19}

El análisis de las trayectorias espaciales de la COVID-19 evidencia que la expansión del contagio no es homogénea, sino que el virus se comporta de manera específica en cada lugar, por ende parece pertinente vincular espacio (geográfico), desigualdad (estructural) y vulnerabilidad (social), a la hora de analizar el comportamiento de la COVID-19. De hecho, en los primeros meses de la pandemia se ha podido identificar determinadas trayectorias espaciales que demuestran cómo ciertas áreas de la ciudad (zonas y barrios más vulnerables) concentraron de manera significativa muchos más contagios que otras. Este comportamiento espacialmente desigual se debe a factores estructurales, principalmente socioeconómicos. Por otro lado, en el campo de la administración pública se ha podido verificar que en aquellas ciudades donde los

7 COronaVIrus Disease (COVID) - Enfermedad de Coronovirus. 
gobiernos locales activaron con anticipación políticas de prevención, posteriormente han logrado un mejor resultado respecto a la evolución de los contagios.

El espacio geográfico expresa, como categoría analítica, múltiples procesos políticos, sociales, económicos y culturales. La relación entre las configuraciones espaciales de hábitat urbano y la salud pública es fundamental para comprender la evolución de las ciudades, e históricamente la ciencia de la geografía de la salud ha descrito desde procesos epidemiológicos relacionados con los contagios por contigüidad, hasta la correlación que hay entre determinantes sociales con el estado nutricional y la esperanza de vida (Pickenhayn, 2006), siendo además que estos procesos epidemiológicos presentan un foco de contagio mayor en las ciudades dadas sus características estructurales de aglomeración. La geografía de la salud se conjuga con otros factores aparentemente externos como son el transporte, la movilidad urbana o la vida cotidiana, que articulan y configuran trayectorias espaciales que influyen en los grados de riesgo de contagio. Por tanto, el análisis geoespacial es un instrumento metodológico que permite monitorear la materialización de los procesos sociales en un determinado contexto geopolítico.

La estructura urbana expresa un fenómeno de aglomeración que, en el contexto de la COVID-19, ha cobrado interés respecto a sus pros y contras a la hora de enfrentar una situación de emergencia. Por ejemplo, Granados (2020) señala que los "efectos de esa concentración en la propagación de enfermedades contagiosas puede ocurrir a mayor velocidad en las ciudades", lo cual es evidente. Por su parte Oriol $\mathrm{Nel} \cdot \mathrm{lo}(2020)$ sostiene que, si bien hay un mayor riesgo en espacios de mayor aglomeración, la concentración urbana "supone también esperanza de salud", pues la infraestructura y los servicios de salud son más accesibles y eficaces en las ciudades.

Es evidente que los debates en torno a la preferencia de una mayor o menor aglomeración urbana, bajo qué parámetros, etc., son un síntoma de la necesidad urgente de discutir los desafíos que la sociedad urbana deberá enfrentar en las próximas décadas. En este sentido, la condición aparentemente paradójica de las ciudades como escenarios de la pandemia demanda un mayor nivel de especificación analítica de las desigualdades estructurales y, más concretamente, de la vulnerabilidad de las personas, las comunidades urbanas y sus determinantes sociales.

Esta investigación plantea la construcción de un modelo que permita correlacionar espacialmente la evolución de los contagios de la COVID-19 con determinantes socioespaciales de vulnerabilidad. El modelo de análisis se sustenta a partir del enfoque de riesgo-amenaza-vulnerabilidad formulado por la Oficina de las Naciones Unidas para la Reducción del Riesgo de Desastre (UNISDR, 2016). Desde esta perspectiva, el nivel de vulnerabilidad frente al efecto potencial de la amenaza de la COVID- $19^{8}$ deriva de las características de las personas o grupos en términos de su morbilidad preexistente, así como de las condiciones sociales, culturales y económicas que influyen en su capacidad para anticipar, hacer frente, resistir y recuperarse de los efectos adversos del coronavirus (UNISDR, 2016).

El conjunto de condiciones sociales, culturales y económicas se materializan en un espacio concreto, sea cual sea su escala, tamaño o localización, de manera que el espacio dialoga estrechamente con el tiempo y la pandemia, estableciendo una arti-

Las amenazas constituyen los procesos, fenómenos o actividad humana que pueden ocasionar muertes, lesiones u otros efectos en la salud, daños a los bienes, disrupciones sociales y económicas o daños ambientales. En el caso del COVID-19, el SARS-CoV-2 es una amenaza de tipo biológico. 
culación que se explica en la conceptualización de los determinantes sociales de la salud (DSS). Los DSS, según la Organización Mundial de la Salud, se definen como:

las circunstancias en que las personas nacen crecen, viven, trabajan y envejecen, incluido el sistema de salud (...) son el resultado de la distribución del dinero, el poder y los recursos a nivel mundial, nacional y local, que depende a su vez de las políticas adoptadas (Tamayo, Besoaín y Rebolledo, 2018, p.97).

Por la propia naturaleza de la amenaza del COVID-19, los determinantes sociales de la salud adquieren una especial significación en relación con la exposición de las personas. La localización de las personas supone, en cada caso, una serie de servicios adquiridos o deficiencias en cuanto a la calidad de la vivienda, del entorno urbano o de la infraestructura de servicios básicos. Junto a estos factores, las capacidades de producción y otros activos humanos tangibles situados en lugares concretos, son determinantes en la explicación del grado de vulnerabilidad social Joan Benach (cit. en Aragó, 2020) señala cómo la desigualdad en salud acostumbra a "depender de factores socioeconómicos como la precariedad, la falta de trabajo, bajas rentas, la vivienda de menos calidad o barrios con servicios más deficientes", por lo que el impacto desigual de la pandemia se debe principalmente "a factores geo-espaciales, demográficos y socioeconómicos" (Kalabikhina, 2020).

La noción de vulnerabilidad puede concebirse como el conjunto de factores de riesgo y amenaza frente a la COVID-19. El concepto nace de la geografía radical como "equivalente a una situación de precariedad socioeconómica que explica la desigualdad frente a la catástrofe" (Sortino Barrionuevo y Perles Roselló, 2017, p.158). Para ellos, el concepto de vulnerabilidad ha evolucionado desde "la mera exposición física a la visión de la teoría social de la desigualdad" u otros planteamientos más integradores "que plantean el riesgo como un problema de adaptación de la sociedad al riesgo" (ibidem).

En este sentido, la noción de vulnerabilidad tiene la capacidad de comprehender el conjunto de factores de riesgo y amenaza a la hora de enfrentar, tanto individual como colectivamente, la COVID-19, ya que la vulnerabilidad puede concebirse como un efecto de determinadas estructuras políticas, económicas y culturales en un contexto de riesgo y/o emergencia (Díaz Caravantes, 2018). Por otro lado, la Federación Internacional de Sociedades de la Cruz Roja ${ }^{9}$ (IFRC por sus siglas en inglés) establece que el grado de vulnerabilidad de las personas y su capacidad de enfrentar los peligros dependen principalmente de factores tanto físicos como socioeconómi$\cos$. Si bien la condición de pobreza acentúa significativamente el grado de vulnerabilidad, puesto que es un factor que aumenta la exposición a una amenaza sin disponer de los recursos necesarios para enfrentarlo, ésta debe ser estudiada desde un enfoque más amplio de las desigualdades como un concepto complementario o explicativo de la pobreza (Ramos Ojeda, 2019).

El Centro Latinoamericano y del Caribe de Demografía (CELADE) plantea un esquema teórico-metodológico sobre la vulnerabilidad social que combina:

Ver https://www.ifrc.org/en/what-we-do/disaster-management/about-disasters/what-is-a-disaster/what-is-vulnerability/ 
i) eventos, procesos o rasgos que entrañan adversidades potenciales para el ejercicio de los distintos tipos de derechos ciudadanos [civiles, políticos, económicos, sociales, culturales, etc.] o el logro de los proyectos de las comunidades, los hogares y las personas; ii) la incapacidad de respuesta frente a la materialización de estos riesgos; y iii) la inhabilidad para adaptarse a las consecuencias de la materialización de estos riesgos (CEPAL, 2002, p.23).

Por lo tanto el análisis requiere de un enfoque multidimensional que explique la exposición a los riesgos y su gestión (Ramos Ojeda, 2019), siendo que el aumento de la vulnerabilidad implica también un incremento del riesgo a una mayor exposición debido a las bajas condiciones de vida (Díaz Caravantes, 2018). Desde una perspectiva geo-espacial parece evidente la pertinencia del "patrón de distribución de los factores de riesgo físico y humanos en el territorio, y la dimensión espacial de los problemas de vulnerabilidad" (Sortino Barrionuevo y Perles Roselló, 2017, p.159). Por lo tanto, la distribución espacial de la población y los bienes y servicios, más las necesidades en cada lugar concreto, son determinantes a tener en cuenta (Buzai, 2019), además de otros factores como la falta de capacidad y de organización social para mejorar la calidad de vida y el acceso a diferentes bienes y servicios (Araujo González, 2015; Huenchuan, 2020).

En definitiva, la noción de vulnerabilidad es una condición actual y potencial producto de un conjunto de determinantes sociales y multidimensionales que interactúan de forma específica derivada de los bajos ingresos, el bajo nivel de acceso al consumo, el desempleo o el empleo informal sin seguro social, la discriminación de género o de etnia, los bajos niveles de escolaridad, los bajos niveles de calidad del hábitat, etc. (Juárez-Ramírez et al., 2014; Vidal Gutiérrez et al., 2014). Pera además, es fundamental insistir en "la comprensión del riesgo como un hecho territorial, consecuencia de la adaptación del patrón de uso humano a las limitaciones del entorno" (Sortino Barrionuevo y Perles Roselló, 2017, p.159) lo cual implica que el análisis de los factores de vulnerabilidad no son elementos deslocalizados que puedan medirse mediante indicadores genéricos de expresión espacial poco definida; por el contrario, de la posición sobre el territorio de los factores depende en gran parte su nivel de fragilidad" (ibídem). La vulnerabilidad social se "construye" en sociedades, lugares y condiciones específicas. La dimensión espacial y la cartografía de la vulnerabilidad (Perles Roselló, 2010) adquiere así un papel esencial para comprender, prevenir y mitigar los impactos de las amenazas.

\subsection{Determinantes sociales y dimensiones de análisis}

Durante estos meses de pandemia son varios los estudios e investigaciones que han enfocado su análisis en los determinantes socioespaciales de la evolución y difusión de contagios por la COVID-19. Estas investigaciones abarcan ciudades dispares y de diversa magnitud. Ejemplos de América Latina son los estudios realizados sobre Buenos Aires o Luján en Argentina (Buzai, 2020), Medellín o Cali en Colombia (Cuartas et al., 2020), o México D.F. (Suárez Lastra et al., 2020). Principalmente, estos trabajos coinciden en considerar determinantes sociales que pueden agruparse en tres dimensiones para el análisis de la vulnerabilidad: la dimensión demográfica, la dimensión socioeconómica y la dimensión de hábitat. 
La dimensión demográfica aborda la estructura y distribución espacial de la población. Para esta dimensión han sido contemplados factores tales como la estructura etaria y la densidad. La estructura etaria es útil a la hora de establecer grupos de población potencialmente más vulnerables. En este sentido, Esteve et al. (2020) subraya la importancia de considerar la estructura etaria de la población y de los hogares para formular políticas más efectivas de confinamiento tanto a nivel general como estratificado por edades y grupos de población. En ese sentido, el Center for Disease Control and Prevention de los Estados Unidos señala que las personas mayores tienen más probabilidades de sufrir una enfermedad grave por la COVID-19, así como un mayor riesgo de morir (Huenchuan, 2020).

Por otro lado, la densidad es un factor de aglomeración que podría acelerar el contagio debido a la naturaleza de la transmisión, convirtiendo a los espacios comunes en potenciales focos de infección. En este sentido, Michael Hooper (2020) define como "sanción urbana" al proceso histórico de dispersión que han experimentado muchas poblaciones por causa de enfermedades infecciosas. Sin embargo, la densidad por sí sola no es un factor determinante ni tiene una relación directa con la propagación de contagios, pues éstos dependen sobre todo de las condiciones socioeconómicas y de la calidad y acceso a los bienes y servicios públicos (Lall y Wahba, 2020). Subirats (2020) señala la siguiente paradoja: si bien la densidad reduce los efectos nocivos del transporte o del sprawl, por otro lado parece tener efectos negativos para la salud pública en el contexto actual, siendo además que las medidas de "distanciamiento social" cuestionan los modelos clásicos de economía urbana (Flint, 2020). Por tanto, parece pertinente relacionar la densidad con otros factores socioeconómicos y de hábitat como la pobreza, hacinamiento o calidad de la vivienda ${ }^{10}$.

La dimensión socioeconómica tiene que ver con factores relacionados a las condiciones de pobreza y de inserción en la vida social y económica. La calidad del empleo muestra que las personas que cuentan con relaciones laborales estables y/o en empleos que permiten una ejecución a distancia (por ejemplo, el "teletrabajo") tienen unas condiciones favorables y más seguras en comparación con las personas que se ven obligadas a salir de su casa para trabajar. Por esto Alessandri (2020) señala que el hecho de estar encerrados en casa o de acceder a tratamientos hospitalarios no es igual para todas las personas (de ahí la controversia de campañas como \#quédateencasa), lo que implica un acceso diferenciado a los servicios básicos. La encrucijada de muchas personas entre poner en riesgo su salud o perder el puesto de trabajo señala que las personas más vulnerables, en situación de dependencia laboral y que no pueden realizar teletrabajo, son las personas más expuestas al contagio.

La crisis económica derivada de la pandemia ha tenido graves repercusiones respecto a la inserción en la vida social y económica. La oleada de desempleo ha supuesto un crecimiento del trabajo informal y, a su vez, un grave descenso en la afiliación a la seguridad social, ya que la pérdida de un empleo formal ha significado una disminución alarmante de aportes a la seguridad social ${ }^{11}$. La condición de

10 Véase José Manuel Gómez Giménez, Grupo de Investigación en Arquitectura, Urbanismo y Sostenibilidad (GIAU+S), del Departamento de Urbanística y Ordenación del Territorio de la ETS de Arquitectura de la Universidad Politécnica de Madrid. Link: https://blogs.upm.es/covid19upm/2020/05/13/conclusiones-de-la-territorializacion-de-la-pandemia-de-covid-19-en-el-area-metropolitana-de-madrid/

11 A nivel nacional 98.271 mujeres y 141.837 hombres se desafiliaron al Instituto Ecuatoriano de Seguridad Social entre los meses de marzo y mayo de 2020, representando Pichincha el $40 \%$ del total. Link: 
afiliación de una persona supone mayoritariamente un trabajo formal con relación de dependencia y el acceso a servicios sanitarios y otras prestaciones, por lo que el precipitado descenso de cotizaciones en los últimos meses refleja que el riesgo de vulnerabilidad social debe haber aumentado considerablemente.

En cuanto a los niveles de escolaridad y el impacto de las medidas políticas de "aislamiento social", la asistencia a las escuelas y colegios fue suspendida en todo el país. En este sentido y con el fin de no interrumpir el año lectivo, el día 16 de marzo el Ministerio de Educación implementó el llamado "Plan Educativo Covid-19" que contiene más de 840 recursos digitales de enseñanza-aprendizaje. Sin embargo, estas medidas de educación virtual son insuficientes con la realidad de muchas familias, debido a que el acceso a la tecnología (informática e Internet) es limitado, sobre todo en el ámbito rural pero también en ciudades. En consecuencia, existe una baja tasa de disponibilidad de dispositivos (computadoras, tablets, celulares) además de una baja conexión a internet, lo cual limita drásticamente el acceso de muchos estudiantes a la educación, especialmente aquellos con bajos recursos que se ven expuestos a una mayor vulnerabilidad.

La tercera dimensión de análisis se refiere a las condiciones de calidad del hábitat. El vínculo que hay entre malas condiciones de vida y la calidad de la salud tiene una amplia trayectoria histórica. Para el análisis de esta dimensión se utilizan variables tales como hacinamiento, calidad de la vivienda y servicios públicos. La tasa de hacinamiento es un factor que influye en la propagación de distintas enfermedades de transmisión por inhalación o contacto, sobre todo en poblaciones con condiciones habitacionales críticas que carecen de un adecuado saneamiento, recolección de residuos y acceso a agua potable. En gran parte de las ciudades latinoamericanas los niveles de hacinamiento son especialmente graves, lo cual se debe al crecimiento exponencial y desordenado de las ciudades que, en consecuencia, generó muchas zonas y barrios urbanos autoconstruidos en condiciones precarias y, con frecuencia, con un limitado acceso a servicios por ubicarse en áreas de riesgo natural.

En esta misma línea, otro factor para tener en cuenta es la calidad de la vivienda dado que las medidas de confinamiento afectan de forma desigual de acuerdo con las condiciones del espacio en donde se habite. La calidad de la vivienda generalmente se mide en función de los materiales de construcción (techo, piso, paredes) y de la seguridad estructural del conjunto de la vivienda, pues estos factores inciden directamente en la salud física y psicológica de los habitantes. Por tanto, si no existe confort vital respecto a las condiciones climáticas de la vivienda (en relación con el confort térmico o ambiental) existe un mayor riego de vulnerabilidad y, por consiguiente, las condiciones de calidad de vida y del hábitat pueden empeorar en relación a las condiciones de salud (Espinosa Cancino y Cortés Fuentes, 2015).

A su vez, hay otros factores vinculados a la vivienda como son los servicios básicos. La calidad del hábitat está directamente relacionada al acceso material a unas condiciones sanitarias, específicamente respecto al acceso a agua potable y alcantarillado, al saneamiento y recolección adecuada de desechos, al alumbrado eléctrico, así como otras fuentes de energía (gas). Sin estos servicios básicos, las medidas de confinamiento y "aislamiento social" incrementan el riesgo y vulnerabilidad para las familias que no cuentan con los servicios básicos mencionados. 


\section{Caso de estudio}

El Distrito Metropolitano de Quito (en adelante DMQ) pertenece a la provincia de Pichincha y es la capital del Ecuador. El centro urbano, sus conurbaciones y áreas rurales alojan a 2.781 .641 habitantes en 2020, según las proyecciones poblacionales del INEC ${ }^{12}$. Si bien el DMQ tiene una amplia zona rural que abarca más del $80 \%$ de su territorio, para esta investigación se ha tomado como área de estudio la zona urbana y periurbana de la ciudad, compuesta por 32 parroquias urbanas y siete parroquias rurales. Esta decisión se ha adoptado mediante un criterio de funcionalidad urbana, a partir de la continuidad del amanzanamiento y la conurbación que producen intensos flujos de las actividades urbanas más allá de los linderos administrativos. Respecto a las unidades de análisis espacial de la investigación se toman las parroquias, las cuales representan la división político-territorial de menor rango.

El estudio de la investigación se ha acotado al tiempo que transcurre del 9 de abril al 3 de junio de 2020, un período determinado por la política de "aislamiento social" durante la "semaforización color rojo" a disposición del Comité de Operaciones de Emergencia (en adelante COE) Nacional. Durante esta fase se adoptaron varias medidas de restricciones sociales (ver Figura 1). Una de las consecuencias más palpables y qué más ha sentido la población tiene que ver con las restricciones de movilidad y desplazamiento, tanto a nivel internacional como interprovincial a las que se sumaron otras decisiones de confinamiento y aislamiento social con el objetivo de evitar o disminuir la dinámica de expansión del virus.

De acuerdo con la cronología de los hitos acaecidos durante el periodo de "aislamiento social" (ver Figura 1), el 11 de marzo del 2020 y mediante Acuerdo Ministerial No 00126-2020 se declaró el "Estado de Emergencia Sanitaria" en el Sistema Nacional de Salud. El 16 de marzo, el COE Nacional solicitó la declaración de estado de excepción y la adopción de medidas en todo el territorio nacional, incluyendo el aislamiento social obligatorio. Adicionalmente, con el propósito de clasificar el estado de cada provincia del país, se estableció un modelo de semaforización (rojo, amarillo y verde, de mayores a menores restricciones) con diferentes niveles de restricciones sociales (Sistema Nacional de Gestión de Riesgos y Emergencias 2020).

El incremento exponencial de casos de contagio en el DMQ hizo que la administración local tomase, a expensas del gobierno nacional, medidas de control más riguroso tales como el cierre de los centros de abastos de la ciudad, en donde se incluye a la mayoría de los mercados y ferias. También el Municipio del DMQ optó por medidas coercitivas en el caso del uso obligatorio de mascarilla con pena de multa. Así mismo, tanto el gobierno nacional como el local anunciaron la realización, aunque de forma limitada y fallida, de un importante número de pruebas PCR que serían aplicadas a trabajadores considerados de mayor riesgo.

E1 28 de abril, el Concejo Metropolitano del DMQ solicitó al COE Nacional mantener la restricción de semáforo rojo. Adicional, tomó medidas complementarias para el periodo de distanciamiento. Por ejemplo, restricciones en el uso del espacio público, restricciones y sanciones por el uso indebido del espacio público por personas diagnosticadas con COVID-19 o en aislamiento obligatorio, suspensión de licencias únicas de actividades económicas, y la aprobación de un plan de restricción vehicular y transporte terrestre mediante Resolución $\mathrm{N}^{\mathrm{o}} \mathrm{A}-038$.

12 Instituto Nacional de Estadísticas y Censos. "Proyecciones Poblacionales", 18 de octubre de 2013. 
Figura 1. Línea de tiempo

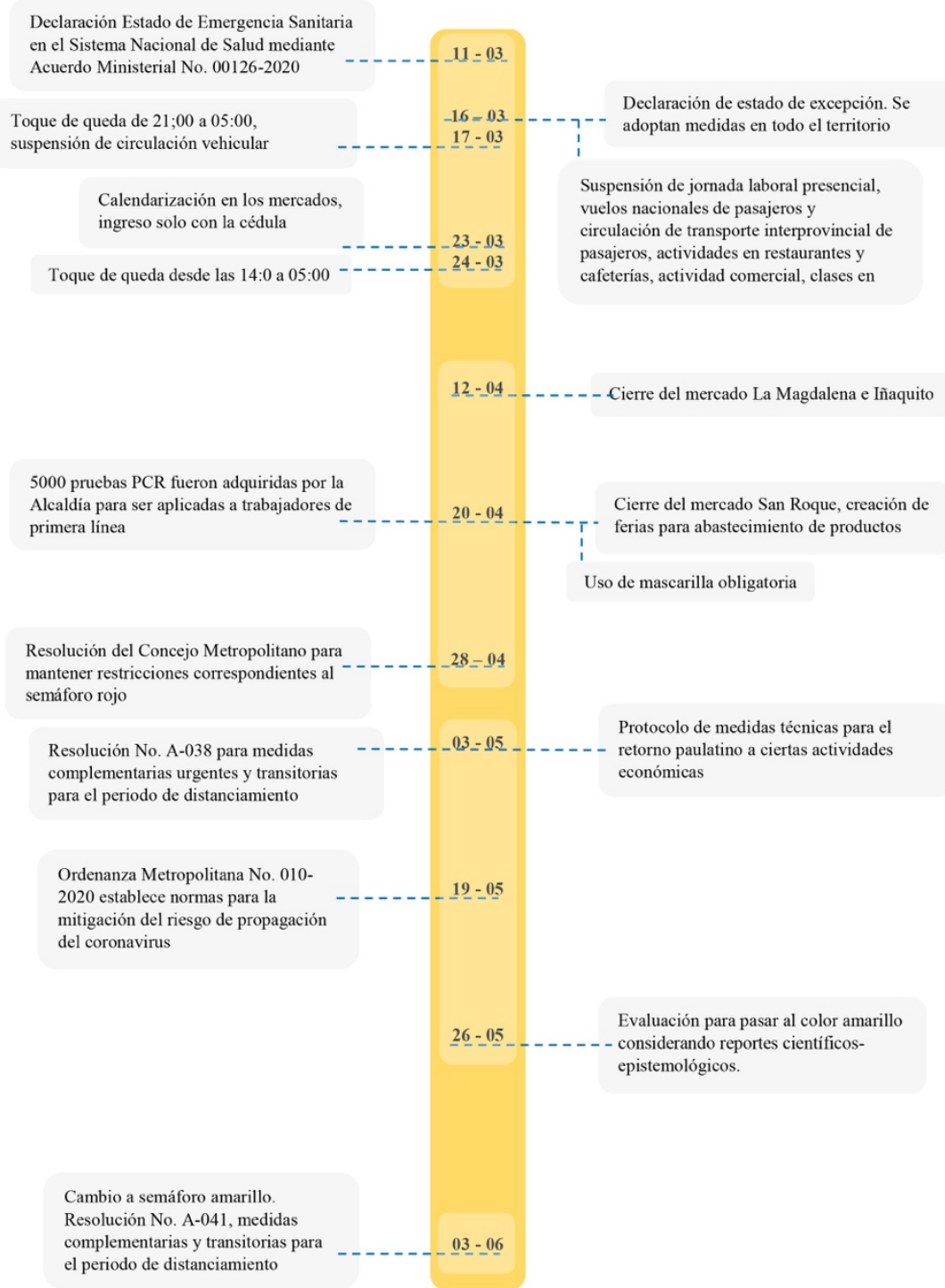

Fuente: Repositorio de documentos emergencia COVID-19 Ecuador. Cámara de Industrias y Producción. Elaboración propia.

El 19 de mayo la Ordenanza Metropolitana No 010-2020 estableció nuevas normas relacionadas con la mitigación del riesgo de propagación del coronavirus. El 26 de mayo se realizó la evaluación para determinar si la situación posibilitaba cambiar el semáforo a color amarillo. Si bien los reportes científicos-epidemiológicos indicaban un posible ascenso de contagios en caso de cambiar el semáforo, el 3 de junio se cambió a semáforo amarillo junto a la implementación de nuevas medidas complementarias urgentes y transitorias para la nueva fase de distanciamiento en el DMQ, mediante resolución $\mathrm{N}^{\circ} \mathrm{A}-041$. 


\section{Metodología}

La metodología aplicada busca establecer un instrumento de análisis que permita monitorear los patrones espaciales vinculando los niveles de vulnerabilidad de la población con las tasas de contagios por COVID-19 en el DMQ, durante el periodo de aislamiento social o semáforo rojo entre el 9 de abril y el 3 de junio de 2020 . Se emplea una metodología de corte cuantitativo-espacial para calcular la evolución y tasas de contagios en el DMQ y obtener un índice de vulnerabilidad y, finalmente, correlacionar los contagios con el índice de vulnerabilidad. La información recopilada se procesa a través de Sistemas de Información Geográfica (SIG) para situarla sobre el espacio, de modo que sea factible la comprensión del territorio y sus dinámicas espaciotemporales para obtener trayectorias espaciales.

Correspondiente a los casos de contagio, se obtiene la información a través de los informes oficiales emitidos con cierta regularidad (a diario o cada pocos días) por el Comité de Operaciones Especiales Provincial (COE) de Pichincha ${ }^{13}$ que recibe los datos del Ministerio de Salud Pública. Así mismo, el COE de Pichincha presentó un portal de cifras del conjunto de la provincia para informar sobre personas confirmadas con COVID-19 por género y grupo etario, fallecidos, casos descartados y número de pruebas tomadas. Las cifras tienen un nivel de desagregación por cantón y parroquia. La información se genera conforme avanza la toma y procesamiento de muestras que realiza el Ministerio de Salud Pública y son emitidas en función de la fecha de inicio de síntomas a través de una infografía de síntesis ${ }^{14}$.

La publicación de los datos y su posterior seguimiento tuvo algunas dificultades respecto a su periodicidad y al grado de desagregación en cantones y parroquias. Durante el periodo que va del 24 al 28 de abril no se publicaron datos por, según informaron las autoridades, actualización de cifras. Mediante un comunicado por parte del Ministerio de Salud Pública se informó que los días 25 y 26 de abril no se emitirían datos debido a que se encontraban consolidando datos a escala nacional, utilizando un nuevo software que facilitase la digitalización de los datos de manera más ágil y eficiente. Por otro lado, se comprobó que varias fechas nunca tuvieron informes emitidos por el COE Provincial de Pichincha, lo cual genera pequeños vacíos de información tal como se detalla en los resultados de este trabajo. Finalmente, durante el periodo de aislamiento social se sucedieron ajustes y cambios en la metodología de contabilización por parte de las autoridades gubernamentales, por ejemplo en lo que respecta al conteo de los casos de contagio en relación con las pruebas utilizadas (PCR o pruebas rápidas). Pese a ello, se trata de las únicas cifras publicadas por los organismos públicos responsables.

Para esta primera parte de la investigación se realiza un análisis descriptivo de la distribución de frecuencias con curva de tendencia e histogramas para representar los casos diarios de contagios y fallecidos. Fueron registrados los contagios según parroquia en las fechas antes mencionadas, para la curva de tendencia se utiliza los registros totales del DMQ y se calcula los casos diarios. De igual manera se realiza

Ver https://coe-pichincha.senescyt.gob.ec/

14 La infografía sobre la situación Pichincha por COVID-19 presenta: casos confirmados, casos descartados, casos con sospecha y muestras tomadas, además se realiza un histograma de casos confirmados por día y la tendencia acumulada de casos a nivel general y por cantones (SENESCYT 2020). 
el registro de personas fallecidas en el DMQ y se obtiene el número diario promedio de fallecidos por COVID-19, permitiendo calcular la tasa de letalidad y mortalidad.

\section{Tasa de letalidad}

La letalidad se define como la proporción de casos de una enfermedad que resultan mortales con respecto al total de casos en un periodo específico. Por tanto, se trata de un indicador de la gravedad de una enfermedad. La tasa de letalidad se calcula con la siguiente fórmula:

$$
L \%=\frac{F}{E} * 100
$$

Siendo: $\mathrm{L}=$ tasa de letalidad.

$\mathrm{F}=$ número de muertes por una enfermedad en un periodo y un área determinados.

$\mathrm{E}=$ número de casos diagnosticados de la misma enfermedad en el mismo periodo y área.

\section{Tasa de mortalidad}

La tasa de mortalidad expresa la dinámica de las muertes ocurridas en la población a través del tiempo y el espacio, la mortalidad general es el volumen de muertes ocurridas en un periodo dado y el tamaño de la población en la que éstas se presentaron, se calcula de acuerdo a la siguiente fórmula:

$$
m_{x}=\frac{F_{x}}{P_{x}} * 10^{n}
$$

Siendo: $\mathrm{m}_{\mathrm{x}}=$ tasa de mortalidad.

$\mathrm{F}_{\mathrm{x}}=$ número de fallecimientos dentro de un conjunto $X$ en el período de tiempo considerado.

$\mathrm{P}_{\mathrm{x}}=$ número total de personas en el conjunto $X$.

$10^{\mathrm{n}}=$ factor de conversión para expresarlo en unidades por cada $1000, \mathrm{o}$ por cada 100000 .

Posteriormente se realizó un análisis espacial para elaborar las cartografías pertinentes utilizando la tasa de prevalencia con algunos cortes temporales para evidenciar su evolución en las 39 parroquias analizadas.

\section{Tasa de prevalencia}

Es una medida de morbilidad que se refiere al número de individuos que en relación con la población total padecen una enfermedad determinada en un momento específico. Se calcula con la siguiente fórmula:

$$
P=\frac{n \text { o de eventos }}{\text { población total }}
$$

Siendo: $\mathrm{P}=$ tasa de prevalencia. 
$\mathrm{N}^{\mathrm{o}}$ de eventos $=$ número total de casos existentes al momento.

Población total = total de la población en el momento.

Tabla 1. Cuadro metodológico

\begin{tabular}{|c|c|c|c|c|}
\hline Dimensión & Indicador & Descripción & Fuente & Categorización \\
\hline \multirow{6}{*}{ Demografía } & \multirow{3}{*}{ Densidad } & \multirow{3}{*}{ Población / hectárea } & \multirow{3}{*}{$\begin{array}{l}\text { CPV } \\
2010\end{array}$} & Menos denso (1) \\
\hline & & & & Más menos denso (2) \\
\hline & & & & Más denso (3) \\
\hline & \multirow{3}{*}{ Edad } & \multirow{3}{*}{$\begin{array}{l}\text { Rangos etáreos vul- } \\
\text { nerables }\end{array}$} & \multirow{3}{*}{$\begin{array}{l}\text { CPV } \\
2010\end{array}$} & $0-40(1)$ \\
\hline & & & & $41-60(2)$ \\
\hline & & & & Más de $60(3)$ \\
\hline \multirow{8}{*}{ Hábitat } & \multirow{2}{*}{$\begin{array}{l}\text { Hacina- } \\
\text { miento }\end{array}$} & \multirow{2}{*}{$\begin{array}{l}3 \text { o más personas den- } \\
\text { tro de un dormitorio }\end{array}$} & \multirow{2}{*}{$\begin{array}{l}\text { CPV } \\
2010\end{array}$} & No $(1)$ \\
\hline & & & & Si (3) \\
\hline & \multirow{3}{*}{$\begin{array}{l}\text { Calidad de } \\
\text { la vivienda }\end{array}$} & \multirow{3}{*}{$\begin{array}{l}\text { Materiales y estado } \\
\text { de: techo, paredes y } \\
\text { piso }\end{array}$} & \multirow{3}{*}{$\begin{array}{l}\text { CPV } \\
2010\end{array}$} & Bueno (1) \\
\hline & & & & Regular (2) \\
\hline & & & & Malo (3) \\
\hline & \multirow{3}{*}{$\begin{array}{l}\text { Servicios } \\
\text { básicos }\end{array}$} & \multirow{3}{*}{$\begin{array}{l}\text { Condiciones de luz, } \\
\text { agua, alcantarillado y } \\
\text { recolección de basura }\end{array}$} & \multirow{3}{*}{$\begin{array}{l}\text { CPV } \\
2010\end{array}$} & Bueno (1) \\
\hline & & & & Regular (2) \\
\hline & & & & Malo (3) \\
\hline \multirow{14}{*}{$\begin{array}{l}\text { Socio-eco- } \\
\text { nómica } \\
\text { (jefe/a de } \\
\text { hogar y } \\
\text { cónyuge) }\end{array}$} & \multirow{3}{*}{ Escolaridad } & \multirow{3}{*}{$\begin{array}{l}\text { Nivel educativo de } \\
\text { el/la jefe/a de hogar y } \\
\text { su cónyuge }\end{array}$} & \multirow{3}{*}{$\begin{array}{l}\text { CPV } \\
2010\end{array}$} & Igual o mejor que pregrado (1) \\
\hline & & & & Colegio (2) \\
\hline & & & & Menor de escuela (1) \\
\hline & \multirow{6}{*}{ Empleo } & \multirow{3}{*}{$\begin{array}{l}\text { Grupo de ocupación } \\
\text { al que pertenece tra- } \\
\text { baja el/la jefe/a de ho- } \\
\text { gar y su cónyuge }\end{array}$} & \multirow{3}{*}{$\begin{array}{l}\text { CPV } \\
2010\end{array}$} & Grupo de ocupación directivos (1) \\
\hline & & & & $\begin{array}{l}\text { Grupos de ocupación administrati- } \\
\text { vos (2) }\end{array}$ \\
\hline & & & & Grupos de ocupación operarios (3) \\
\hline & & \multirow{3}{*}{$\begin{array}{l}\text { Rama de actividad en } \\
\text { la que trabaja el/la } \\
\text { jefe/a de hogar y su } \\
\text { cónyuge }\end{array}$} & \multirow{3}{*}{$\begin{array}{l}\text { CPV } \\
2010\end{array}$} & $\begin{array}{l}\text { Actividades económicas con ingre- } \\
\text { sos medio-alto y alto (1) }\end{array}$ \\
\hline & & & & $\begin{array}{l}\text { Actividades económicas con ingre- } \\
\text { sos medio (2) }\end{array}$ \\
\hline & & & & $\begin{array}{l}\text { Actividades económicas con ingre- } \\
\text { sos medio-bajo y bajo (3) }\end{array}$ \\
\hline & \multirow{2}{*}{$\begin{array}{l}\text { Seguridad } \\
\text { social }\end{array}$} & \multirow{2}{*}{$\begin{array}{l}\text { Afiliación al seguro } \\
\text { social }\end{array}$} & \multirow{2}{*}{$\begin{array}{l}\text { CPV } \\
2010\end{array}$} & Tiene si (1) \\
\hline & & & & No tiene (3) \\
\hline & \multirow{3}{*}{$\begin{array}{l}\text { Pobreza por } \\
\text { consumo }\end{array}$} & \multirow{3}{*}{$\begin{array}{l}\text { Hogares con ingreso } \\
\text { o consumo que se } \\
\text { ubica por debajo del } \\
\text { costo de la canasta } \\
\text { básica }\end{array}$} & \multirow{3}{*}{$\begin{array}{l}\text { Encuesta } \\
\text { de condi- } \\
\text { ciones de } \\
\text { vida } 2014\end{array}$} & $1-7 \%(1)$ \\
\hline & & & & $8-14 \%(2)$ \\
\hline & & & & $15-22 \%(3)$ \\
\hline
\end{tabular}

Fuente: Elaboración propia.

Por otro lado, para la construcción del índice de vulnerabilidad se diseña un modelo metodológico a partir de tres dimensiones analíticas: una dimensión demográfica, una dimensión de condiciones socioeconómicas y una dimensión de calidad del hábitat (ver Tabla 1). Para estandarizar los valores de cada tipo de indicador, se opta por categorizar en base a tres valores ( 1 a 3 ) que indican el nivel de vulnerabilidad socioespacial. El valor 1 indica "menos vulnerable", el valor 2 indica "más-menos vulnerable", y el valor 3 indica "más vulnerable". 
Para el cálculo de los indicadores que conforman el índice de vulnerabilidad, los datos son obtenidos del último Censo Nacional de Población y Vivienda ${ }^{15}$, y son procesados a través del software REDATAM S+ facilitado por la CEPAL. Este software permite analizar las bases de datos de los censos hasta el nivel de desagregación más bajo, que equivale a una manzana. Para esta investigación el nivel de desagregación empleado es el sector censal y, posteriormente, un nivel parroquial como unidad de análisis socioespacial. Es pertinente señalar que, teniendo en cuenta que el área de estudio corresponde al espacio urbano y periurbano del DMQ, se incluyen únicamente los sectores censales que dan continuidad al amanzanamiento de la trama urbana. Esto permite que los datos no se distorsionen, dado que las parroquias rurales dispersas contienen superficies hasta $2000 \%$ más grandes que las urbanas.

Tras obtener los datos de los indicadores para cada dimensión se realiza una suma-producto en función de la categorización previamente establecida. Al obtener los valores de cada indicador se procede al cómputo de cada dimensión con valores equidistantes. Finalmente, para el cómputo del índice de vulnerabilidad se otorga una ponderación diferenciada a cada dimensión: $20 \%$ para la dimensión demográfica, $40 \%$ para la dimensión de hábitat y $40 \%$ para la dimensión de condiciones socioeconómicas. Esta ponderación guarda relación con el número de indicadores por dimensión, además de prever una posible sobrevalorización del indicador de densidad por ser el área de estudio un espacio urbano.

\section{Resultados}

\subsection{Análisis de la evolución de los contagios en el DMQ}

Figura 2. Evolución de casos confirmados por COVID-19 en el DMQ

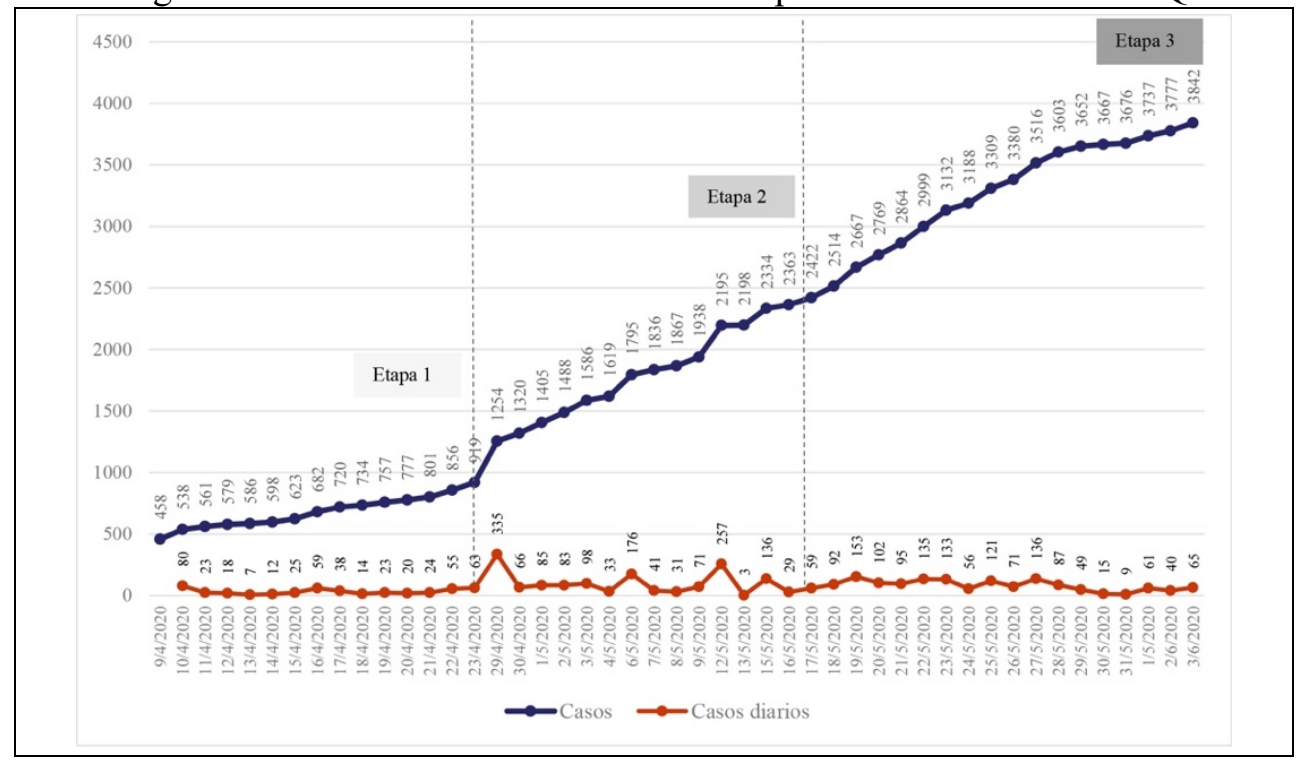

Fuente: COE Provincial de Pichincha. Elaboración propia.

15 Realizado por el Instituto Nacional de Estadística y Censo (INEC). 
Los casos confirmados por contagio de COVID-19 en el DMQ entre el 9 de abril al 3 de junio de 2020 — período de aislamiento social o semáforo rojo- fueron 3.842 con tres etapas claras (ver Figura 2).

La primera etapa ( 9 al 23 de abril) se caracteriza por un lento crecimiento con un total de 919 casos. La segunda etapa ( 24 de abril al 17 de mayo) constata un incremento porcentual en los casos de contagio, siendo una curva más pronunciada y llegándose a registrar hasta 335 casos en solo cinco días. Finalmente, la tercera etapa ( 18 de mayo al 3 de junio) refleja una continuidad en el ritmo constante de contagios. A lo largo de todo el periodo analizado hay una tendencia claramente ascendente.

El análisis de la evolución de los contagios puede verse de forma más detallada a partir del promedio de casos diarios. En el periodo analizado el promedio de casos diarios es de 70. En la gráfica (ver Figura 2) se observa que entre el 22 de abril y el 3 de mayo hay un aumento constante en la cantidad de casos confirmados. En los siguientes días los registros son variables, habiendo puntos de inflexión en días señalados que muestran un notable aumento en los casos diarios como, por ejemplo, en los días 19 y 27 de mayo, en que se contabilizan 153 y 136 respectivamente. Estos datos, aparentemente inconexos, muestran las irregularidades en la información facilitada por los organismos responsables.

Figura 3. Número de fallecidos por día

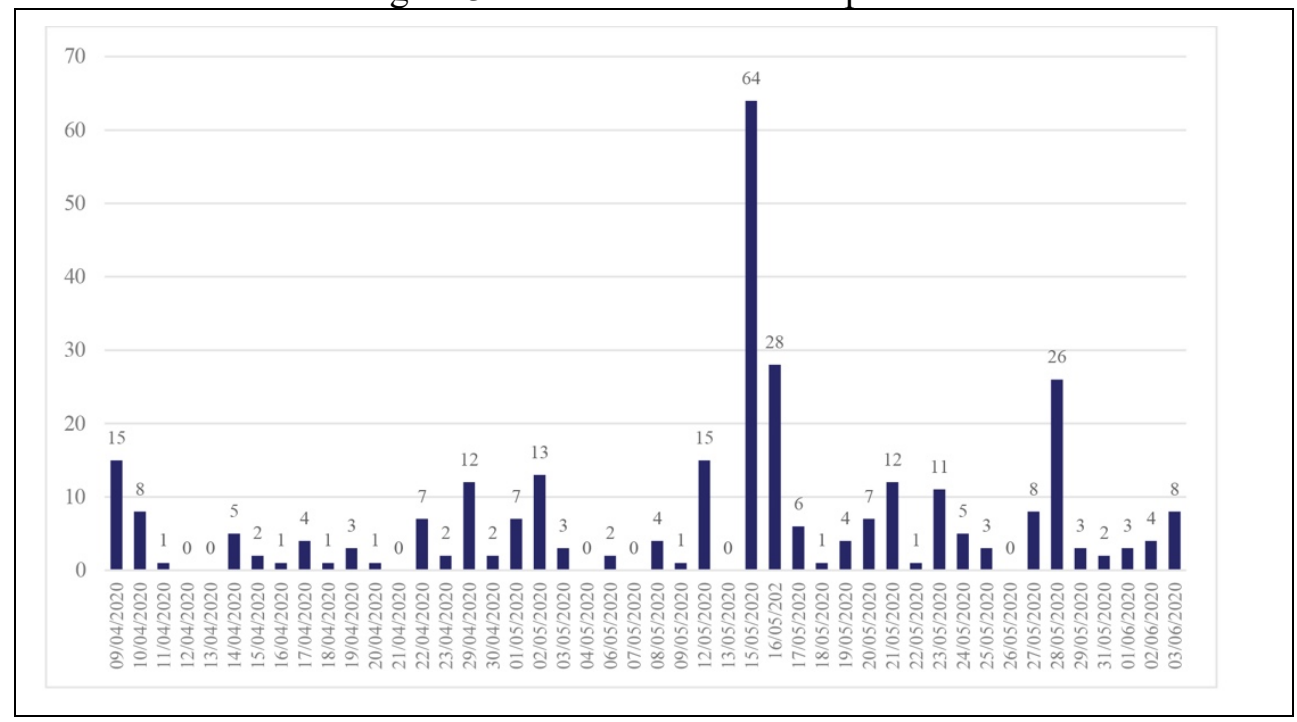

Fuente: COE Provincial de Pichincha. Elaboración propia.

Además de los datos de contagios, es fundamental registrar también la evolución de personas fallecidas por COVID-19 (ver Figura 3). El primer reporte, del 9 al 12 de abril, se presentó un acumulado de 15 personas fallecidas con un promedio de 6 fallecidos diarios. Los registros del 13 al 15 de mayo evidencian un aumento exponencial de fallecidos y generando un punto de inflexión en la tendencia global del periodo analizado, ya que la evolución de fallecidos regresó inmediatamente a los datos intermitentes de las semanas previas al 15 de mayo. 
En definitiva, el periodo analizado (9 de abril al 3 de junio) alcanzó un total de 305 fallecidos y 3.842 casos confirmados, con una tasa de letalidad de 7,93\%. En este sentido, la Organización Mundial de la Salud (OMS) señaló a finales de marzo que la tasa promedio de letalidad del COVID-19 oscila entre el 3\% y $4 \%{ }^{16}$, situando a Ecuador como uno de los países con mayor tasa de letalidad. Por otro lado, la tasa de mortalidad hasta el 3 de junio fue de 4,88 fallecidos por cada 100.000 habitantes.

Figura 4. Tasa de mortalidad por COVID-19 en el Distrito Metropolitano de Quito

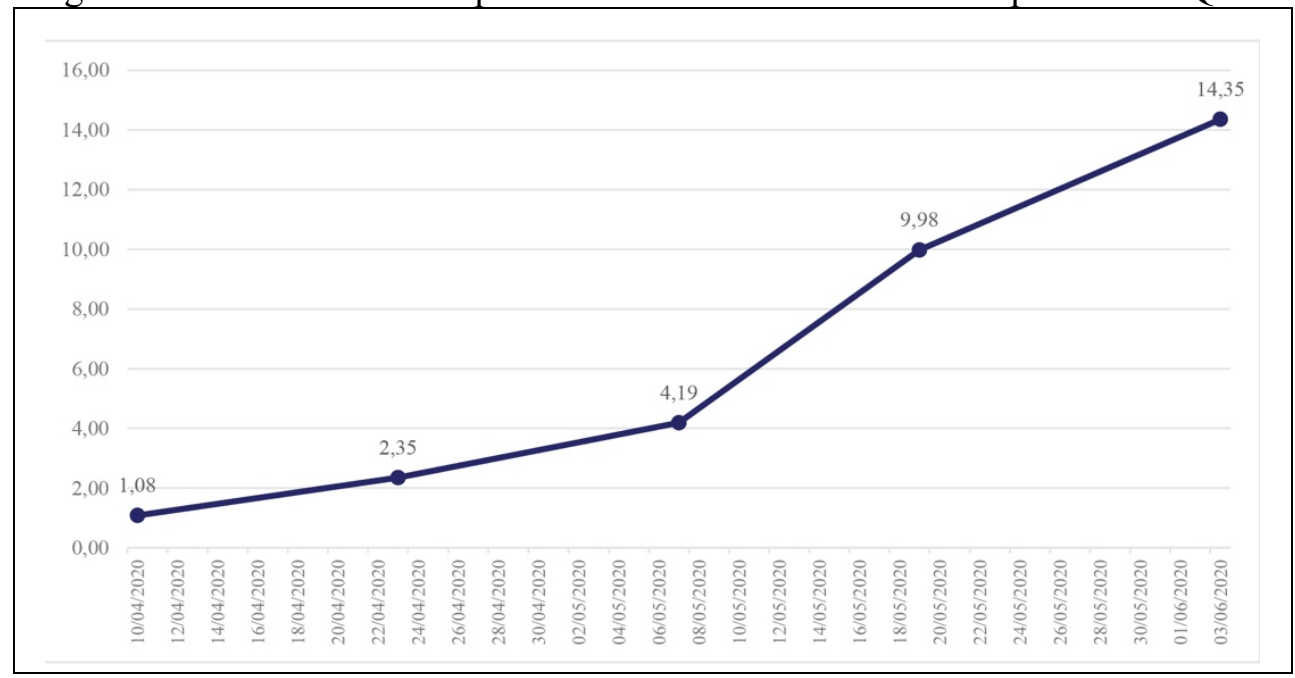

Fuente: COE Provincial de Pichincha. Elaboración propia.

Debido a las evidentes dificultades en la toma y procesamiento de las pruebas tanto PCR como rápidas ${ }^{17}$, así como en el registro de la información proveniente de las mismas (la metodología de procesamiento de datos fue modificada por los organismos gubernamentales responsables, ya que en las primeras semanas se sumaban tanto las pruebas PCR como las pruebas rápidas), la tasa de mortalidad es particularmente importante para valorar el comportamiento de la pandemia. Esto se debe a la mayor certeza del registro de defunción en contraposición al registro de contagios, incluso teniendo en cuenta que hay probablemente un número de fallecidos no contabilizados en el registro oficial.

\subsection{Tendencias de distribución espacial}

Para el análisis de las tendencias de distribución espacial de los casos de contagio respecto a la tasa de prevalencia se consideraron las 39 parroquias del DMQ realizando una cartografía por cada fecha de corte. En la Figura 5a se observa cómo en el primer corte del 10 de abril, las parroquias de Cotocollao e Iñaquito (sector centronorte del DMQ) presentan un mayor número de casos de contagio, siendo la tasa de prevalencia relativamente alta con porcentajes de $0,122 \%$ y $0,087 \%$ en cada una.

\footnotetext{
16 Ver https://www.paho.org/hq/index.php?option=com_content\&view=article\&id=15760:similarities-and-differences-covid-19-and-influenza\&Itemid=1926\&lang=es

17 Se trata de pruebas de identificación de antígenos que no tienen valor diagnóstico.
} 
Figura 5. Tasa de prevalencia con cortes temporales

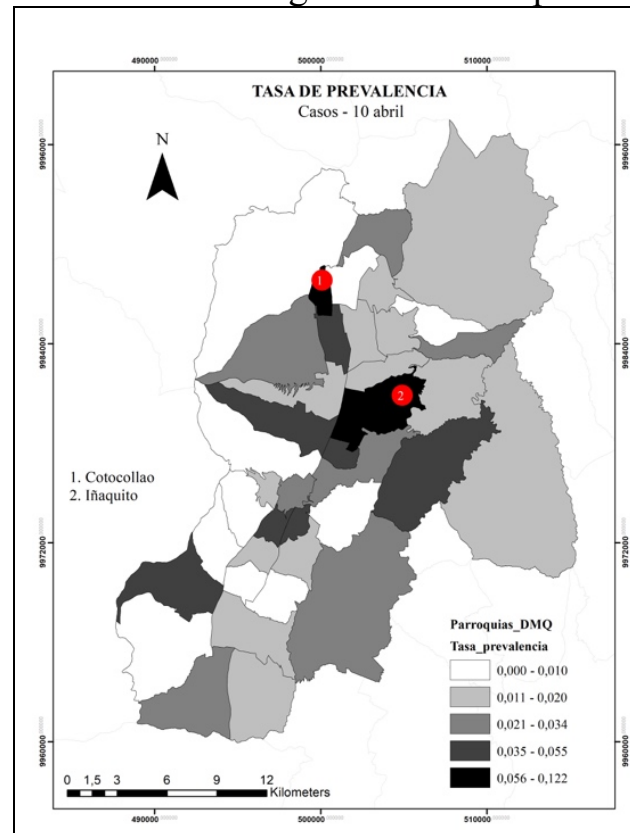

(a)

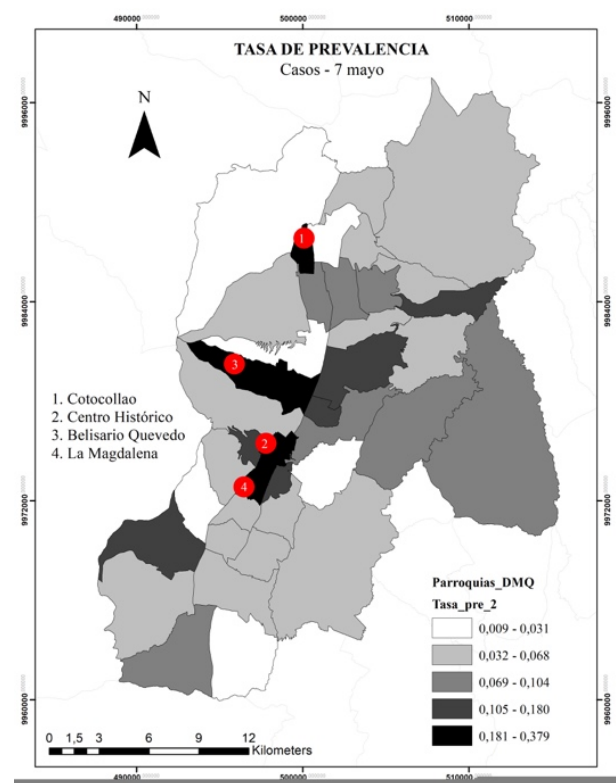

(c)

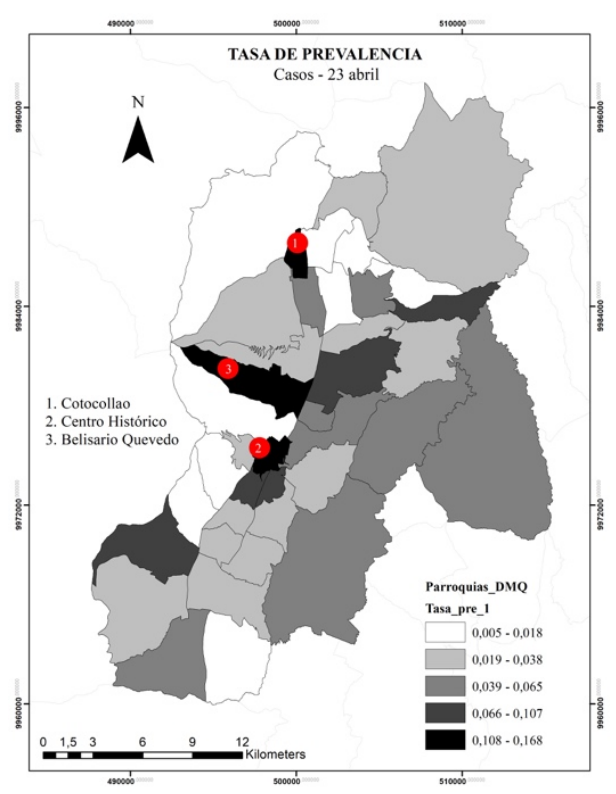

(b)

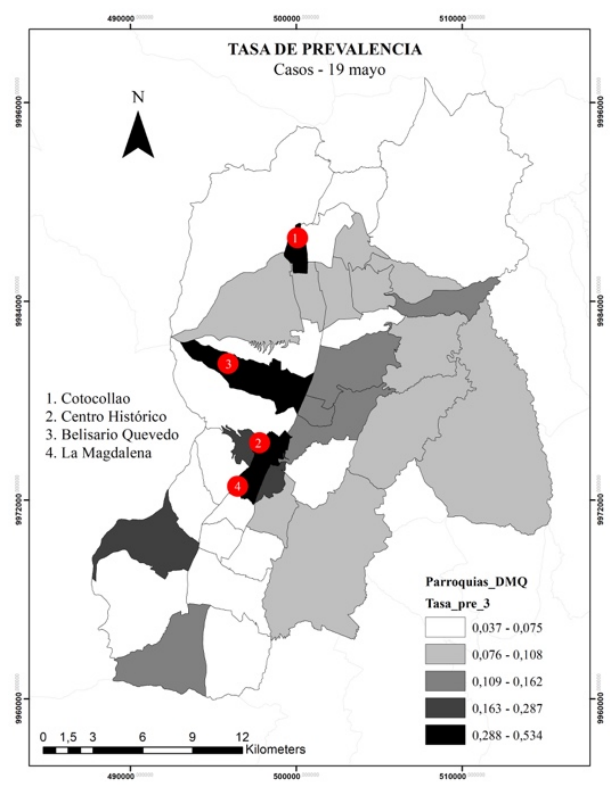

(d)

Fuente: COE Provincial de Pichincha. Elaboración propia. 
El segundo corte (Figura 5b) del 24 de abril muestra una cierta continuidad respecto al corte anterior, ya que se mantiene una tasa alta de prevalencia en la parroquia Cotocollao con 51 casos de contagio. Además, irrumpe negativamente la parroquia del Centro Histórico con una tasa alta de prevalencia al sumar hasta 48 casos de contagios. En el tercer y cuarto corte temporal del 7 y 19 de mayo (Figura 5c y 5d) se mantiene una tasa alta de prevalencia en cuatro parroquias: Cotocollao, Centro Histórico, Belisario Quevedo y La Magdalena, presentando todas ellas un notable incremento de casos. Es importante mencionar que, a pesar de que hay otras parroquias que durante este periodo de tiempo también presentan un incremento de casos de contagio, estas parroquias tienen un mayor número de habitantes $\mathrm{y}$, por tanto, su tasa de prevalencia es menor.

Finalmente, el último corte del 3 de junio refleja el último periodo analizado (ver Figura 6), fecha en que el DMQ pasó de semáforo rojo a amarillo. Este último corte muestra una tasa de prevalencia alta en las cuatro parroquias con más casos confirmados (parroquias de Cotocollao, Centro Histórico, Belisario Quevedo y La Magdalena), lo cual permite conformar un patrón espacial diferenciado. Además, vale la pena indicar que hay otras parroquias en las que se concentran un mayor incremento de casos como son los casos de Guamaní y Chillogallo, pero que en la medida en que tienen una población mayor su tasa de prevalencia es más baja.

Figura 6. Tasa de prevalencia (corte 3 de junio)

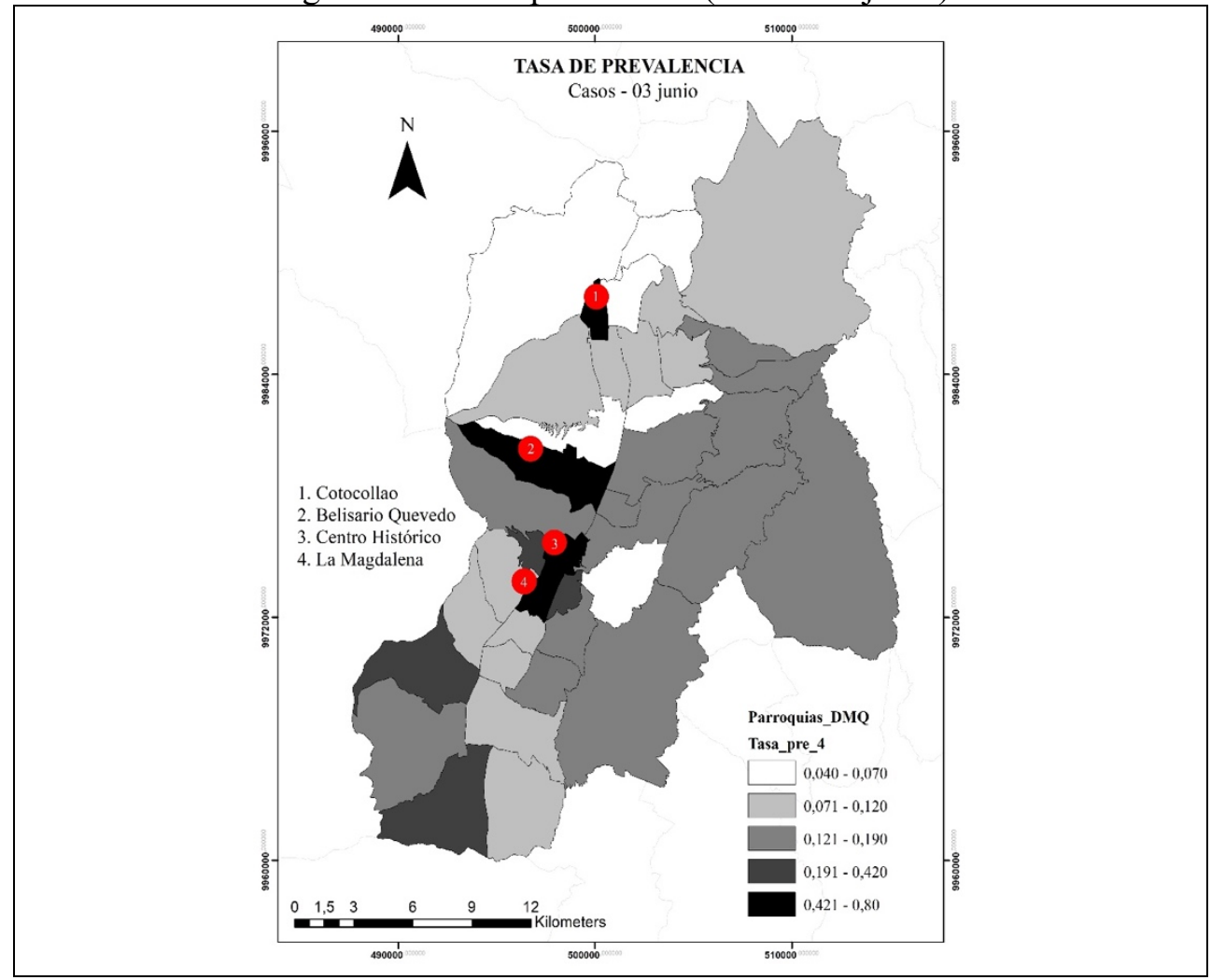

Fuente: COE Provincial de Pichincha. Elaboración propia. 


\subsection{Resultados de las dimensiones del índice}

El análisis e interpretación de los resultados obtenidos se realiza a través de las dimensiones del modelo analítico, para luego obtener un resultado integral a través del índice de vulnerabilidad (ver Tabla 1).

La dimensión demográfica ofrece valores que oscilan entre 1 y 2,69. A partir de la información obtenida respecto a esta dimensión, se reconoce que las parroquias del sur de la ciudad, además de otras dos parroquias situadas en torno al centro histórico, son las parroquias más vulnerables en cuanto a indicadores etarios y de densidad. A su vez, en el extremo nororiental la parroquia Comité del Pueblo es la que presenta un índice mayor de vulnerabilidad tal como puede observarse en la Figura 7a.

La dimensión de hábitat ofrece valores que oscilan entre 1 y 1,84 , lo cual indica que las condiciones de calidad de la vivienda y de acceso a servicios básicos no son tan críticas en el DMQ. En la Figura 7b se observa que las parroquias que reflejan una mayor vulnerabilidad respecto a la calidad del hábitat se localizan en la zona central de la ciudad, correspondiente al Centro Histórico y en las parroquias del extremo norte y sur. En estos casos se trata de las parroquias más alejadas del centro logístico y económico del DMQ, con una menor accesibilidad a ciertos servicios básicos, además de ser zonas urbanas que emergieron en las últimas décadas de forma desordenada y que hoy en día todavía carecen de ciertos estándares de calidad de hábitat.

La última dimensión vinculada a las condiciones socioeconómicas refleja unos resultados mucho más explícitos (ver Figura 7c). En este caso, los valores ponderados oscilan entre 1 y 2,83 , lo que indica que hay un nivel de vulnerabilidad alta, tomando en cuenta que 3 es el valor máximo de vulnerabilidad.

Esta dimensión evidencia la profunda desigualdad social que existe en el área urbana y periurbana del DMQ. Las parroquias de los sectores centro y sur de la ciudad, especialmente en los flancos del Volcán Pichincha y al oriente, en las zonas de expansión urbana, son generalmente las parroquias más vulnerables en términos socioeconómicos. Así mismo, las parroquias nororientales de Calderón y Comité del Pueblo también evidencian un grado alto de vulnerabilidad.

Los valores de vulnerabilidad socioeconómica coinciden con la histórica estructura socioespacial del DMQ ideado por Jones Odriozola (1942-45). En esta estructura se promulgó que el centro y sur se ubiquen los estratos de escasos recursos (clase obrera) que ahora no tienen la oportunidad de "quedarse en casa". Algo similar ocurre en las nuevas periferias al norte de la ciudad, espacios urbanos que alojan a nuevos barrios de estratos populares que no encontraron suelo accesible en zonas más céntricas de la ciudad.

\subsection{Resultados del Índice de Vulnerabilidad}

Para obtener una visión global e integrada de las tres dimensiones analizadas (demográfica, hábitat y socioeconómica) se realiza una superposición ponderada. El índice de vulnerabilidad refleja una relación estrecha con la dimensión socioeconómica, en la medida en que el valor máximo del índice de vulnerabilidad es de 2,10 mientras que el valor máximo de la dimensión socioeconómica es de 2,83. 
Figura 7. Dimensiones de análisis e índice
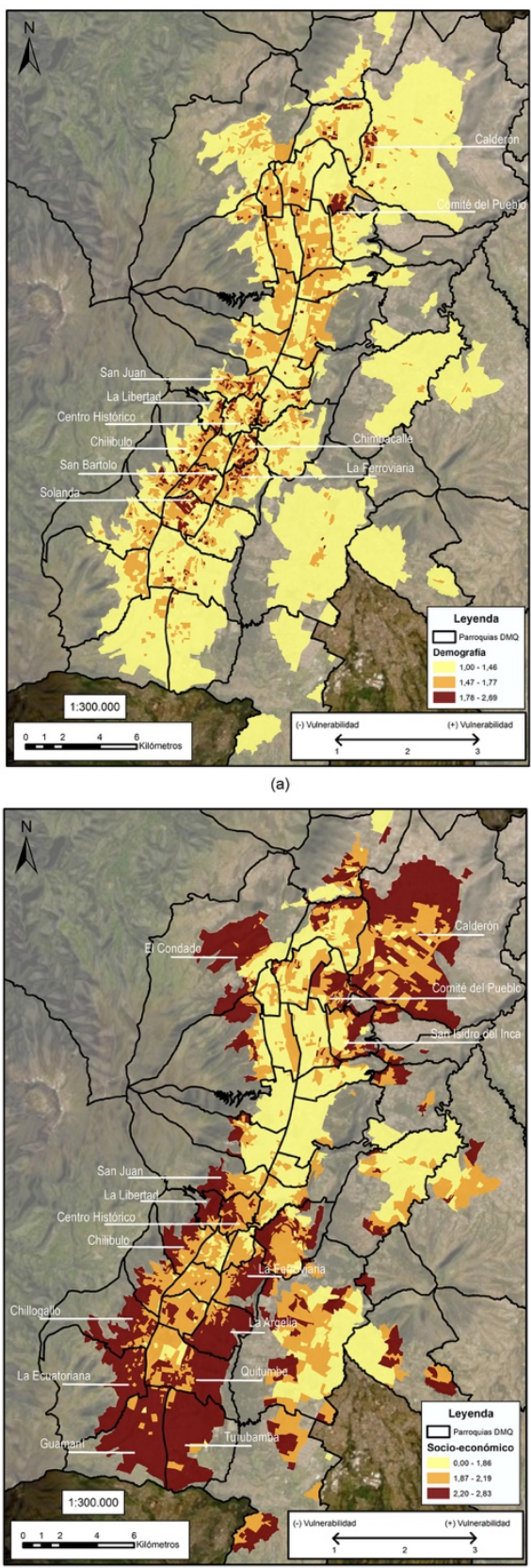

(c)

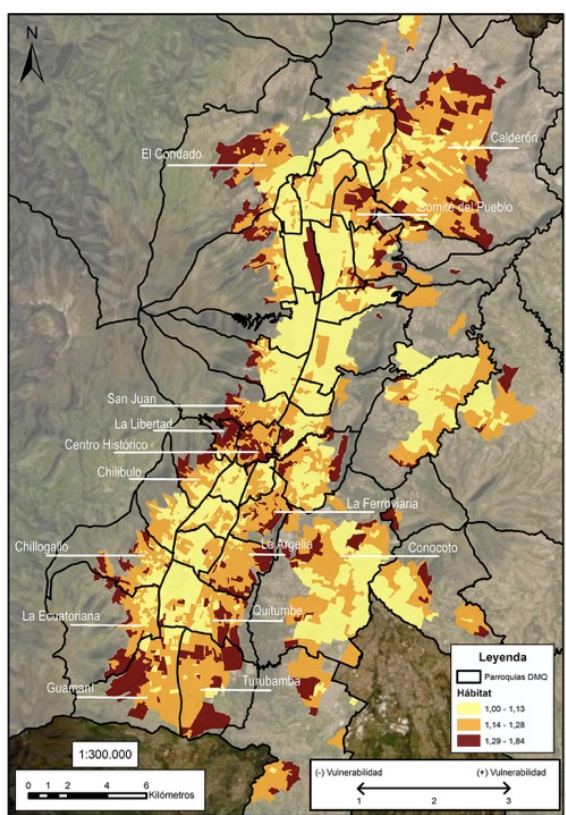

(b)

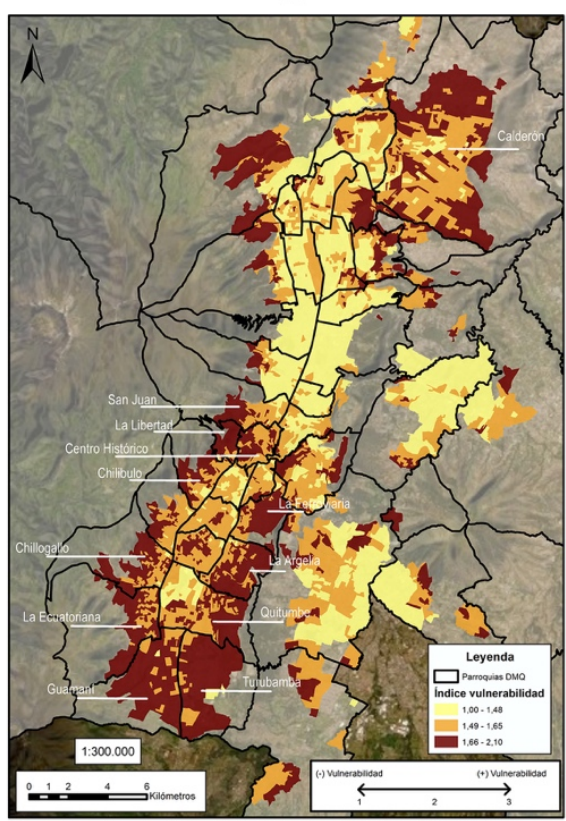

(d)

Fuente: Elaboración propia. 
En este sentido, cabe mencionar que, en términos generales, el área de estudio refleja una vulnerabilidad media. Sin embargo, dentro de esa vulnerabilidad media puede identificarse zonas más críticas como las zonas del centro, sur y extremo norte de la ciudad. En definitiva, el índice de vulnerabilidad (ver Figura 7c y 8) permite evidenciar las desigualdades socioespaciales que se producen en el espacio urbano del DMQ. Del mismo modo, el índice permite visualizar con claridad que las zonas potencialmente más vulnerables por cuestiones demográficas, de hábitat $\mathrm{y}$, principalmente, por cuestiones socioeconómicas, son también las zonas urbanas que presentan un número más alto de casos de contagio confirmados.

Figura 8. Mapa del Índice de Vulnerabilidad

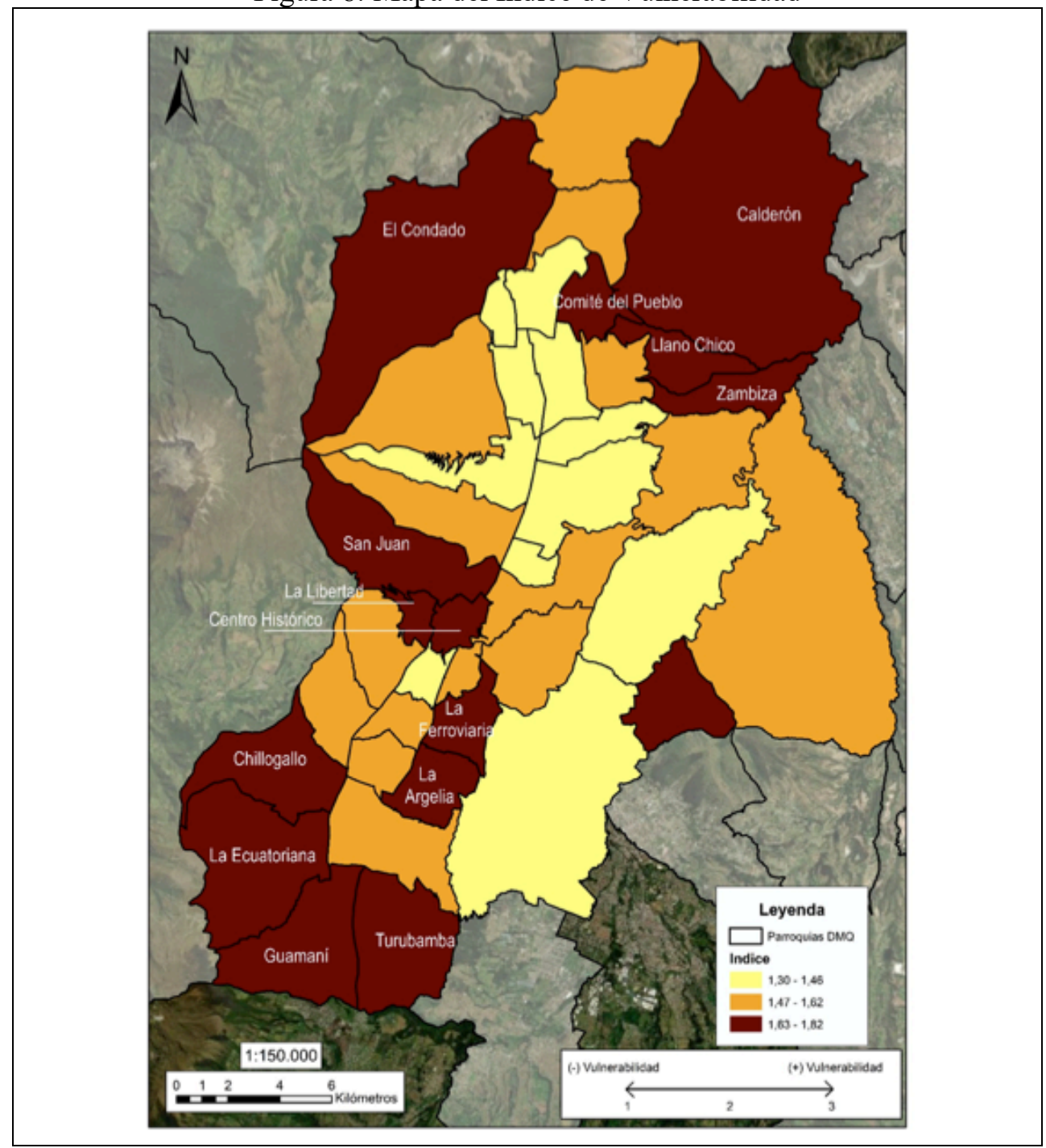

Fuente: Elaboración propia. 


\section{Discusión y reflexiones finales}

Los resultados obtenidos permiten emitir algunas valoraciones con el objeto de enriquecer el debate en torno a la evolución de los contagios de la COVID-19, las tendencias espaciales obtenidas y las decisiones políticas efectuadas por las instituciones gubernamentales durante el periodo analizado.

1. La investigación muestra que las tasas de prevalencia y mortalidad mantuvieron una tendencia ascendente en el área de estudio durante el periodo analizado. Si bien la trayectoria muestra algunos matices en la pendiente de la curva de contagios, la tendencia general es ascendente sin vislumbrar que disminuyese a corto plazo. Pese a los datos mencionados, las instituciones gubernamentales decidieron tomar medidas hacia la normalización y flexibilización del confinamiento cuando aún era palpable la tendencia ascendente de los casos de contagio.

2. Los datos obtenidos y procesados permiten establecer tres fases diferenciadas de comportamiento espacial de los contagios. La primera fase muestra un comportamiento relativamente controlado, con una curva de contagios levemente ascendente y con una baja tasa de fallecimientos. La segunda fase muestra un comportamiento más agresivo en cuanto a la evolución de los contagios que luego se atenúa. Durante esta fase hay un desajuste respecto de la publicación de información, en parte como consecuencia del tiempo de retraso de las pruebas realizadas. La tercera fase establece una continuidad respecto a la trayectoria ascendente de los casos de contagio, con leves impases de disminución de los casos, pero manteniendo una curva constante. Los datos disponibles muestran que la decisión de cambiar de fase del confinamiento estricto (semáforo rojo), a uno parcial (amarillo) no tenía sustento en la tendencia de los comportamientos de contagios y fallecidos.

3. Además del análisis de la evolución del número de contagios, la investigación muestra una específica trayectoria espacial en la que es posible discernir algunos momentos a lo largo de los cortes temporales realizados. El corte base que se realiza en el análisis ( 10 de abril), que coincide con la activación de las alertas de la pandemia en el DMQ, el mayor número de contagios se localiza en las parroquias de Iñaquito y Cumbayá, siendo Iñaquito la parroquia urbana con la tasa de prevalencia más alta del área de estudio. Estas dos parroquias tienen una población de estrato socioeconómico medio-alto y alto, con una mayor movilidad y un mayor número de contactos nacionales e internacionales. Esto es compatible con la llamada fase 1 o de casos importados del virus, es decir el contagio debido a la circulación global debido a viajes y relaciones con posibles contagiados de otros lugares.

4. En los subsiguientes cuatro cortes temporales se observa una progresión en cuanto al desplazamiento espacial en el incremento de contagios, desde parroquias poco densas de clases medias y altas hacia parroquias más densas y con estratos socioeconómicos más pobres. En efecto, parroquias como Belisario Quevedo, Centro Histórico, Cotocollao, Carcelén o La Magdalena, pese a sus localizaciones geográficas dispares en el DMQ, tienen en común tasas de prevalencia significativamente más altas al final del periodo analizado. Estos datos dan cuenta de que estaba en pleno desarrollo la llamada 
fase comunitaria, es decir aquella en la que los contagios adquieren una dinámica local derivada de las relaciones entre los miembros de la comunidad. Pese a los niveles de segregación socioespacial y a las medidas de confinamiento no dejó de producirse un flujo de personas entre los distintos sectores de la ciudad. En definitiva, se produjo un incremento de casos y, a la vez, un desplazamiento desde sectores medios/altos hacia sectores populares.

5. La tendencia de las trayectorias espaciales corresponde a los resultados obtenidos del índice de vulnerabilidad que ha sido construido en este trabajo. Los valores más altos del índice de vulnerabilidad se sitúan en las zonas delimitadas que corresponden a tres grupos de parroquias. El primer grupo se sitúa en el sur de la ciudad, cuyas parroquias más vulnerables corresponden a Guamaní, Turubamba, Argelia y Chillogallo. Un segundo grupo se localiza en el centro de la ciudad, cuyas parroquias más vulnerables son La Libertad, Centro Histórico. El tercer grupo se localiza en la zona norte extremo, cuyas parroquias más vulnerables son Calderón, Carapungo y Cotocollao. Estas parroquias se encuentran en distintas áreas de la ciudad y comparten características de altos niveles de pobreza, empleo de menor calidad, baja escolaridad; al mismo tiempo, son zonas con densidades más altas respecto a la media del DMQ y, en particular, de las parroquias de clases medias y altas cuya densidad es muy baja.

6. La investigación da cuenta de una asociación espacial entre la vulnerabilidad social y el grado de expansión de los contagios. La densidad urbana por sí sola no es un factor determinante para comprender la evolución espacial de los contagios. Por el contrario, las zonas de más alto contagio combinan más variables, sobre todo niveles de desigualdad socioeconómica, siendo éste el indicador más sensible al índice de vulnerabilidad y más explicativo respecto a la expansión de los contagios.

7. Estos factores incluyen la brecha en las condiciones de hábitat y la calidad de la vivienda. Campañas como el \#quedateencasa se viven de modo muy diverso según la situación particular de cada familia. Por un lado, un sector reducido de la población dispone de la comodidad de habitar en una vivienda dotada de servicios, con la capacidad de ejercer el teletrabajo y el acceso a sistemas de adquisición que le permiten cumplir el confinamiento. En el otro extremo, un amplio sector de la población vive en condiciones de hacinamiento, en viviendas precarias, con carencia de servicios básicos. Así mismo, el grado de exposición al contagio de las familias más vulnerables es más alto tanto por la naturaleza de los sistemas de comercialización y abastecimiento (intensos, presenciales y localizados en mercados populares), como por la necesidad de lograr algún tipo de ingreso diario para sus familias a través de la economía informal (fenómeno que se ha profundizado por la expansión del desempleo y la correspondiente desafiliación de miles de personas del seguro social).

8. Las diferencias de vulnerabilidad social a la hora de enfrentarse a la pandemia de la COVID-19 actualiza el debate sobre la insostenible desigualdad urbana. Las medidas de confinamiento social actúan sobre realidades diferentes y, por lo mismo, sus efectos son desiguales. El confinamiento profundiza las desigualdades de los sectores más vulnerables que viene acompañado de un discurso oficial por parte de las instituciones gubernamentales 
que hablan de una supuesta "indisciplina social" con un enfoque disciplinario de orden público en lugar de la adopción de políticas de redistribución y protección social.

9. El trabajo ha enfrentado la penosa situación de no disponer de información adecuada. A lo largo de estos meses se ha modificado en varias ocasiones las metodologías de consolidación de los casos positivos, incluso en función del tipo prueba, rápida o PCR, y han sido evidentes la escasísima capacidad diagnóstica y la abismal brecha entre los fallecimientos con diagnóstico de COVID y la sobremortalidad registrada en el periodo. Sin una base adecuada y abierta de información resulta prácticamente imposible formular adecuadas políticas públicas para reducir, mitigar y prevenir la tendencia ascendente de los contagios y permitir un rol activo de la sociedad civil en general y del mundo académico en particular.

10. La utilización del sistema conceptual de riesgo y vulnerabilidad social ha permitido una aproximación adecuada para comprender los distintos comportamientos en la evaluación de la COVID-19 y producir un índice y una cartografía de la vulnerabilidad. Los resultados obtenidos muestran la concurrencia de factores como la calidad del empleo, del hábitat, del acceso a una vivienda digna y de calidad, y al acceso a servicios básicos como son una educación de calidad y una sanidad pública y universal. Por tanto, una política pública que aspire a dar respuestas en beneficio de la población más vulnerable, tanto en el contexto de la COVID-19 como en un cercano futuro contexto post-COVID, debería recuperar los fundamentos que conforman el derecho a la ciudad.

\section{Referencias}

Alessandri, A. F. (2020). O eclipse da cidade e os "sem direitos". Le Monde Diplomatique, 25 de abril. Recuperado de https://diplomatique.org.br/o-eclipse-da-cidade-e-os-sem-direitos/

Aragó, L. (2020). ¿A qué rentas afecta más el virus? Diario La Vanguardia, 26 de abril. Recuperado de https://www.lavanguardia.com/vida/20200426/48684875052/covid-desigualdad-rentas-afecta-mas-virus.html

Araujo González, R. (2015). Vulnerabilidad y riesgo en salud: ¿dos conceptos concomitantes? Novedades en Población, (210), 89-96.

Buzai, G. (2019). Geografía de la Salud con Sistemas de Información Geográfica. Aplicaciones en el núcleo conceptual del análisis espacial. Anuario de la División Geográfica, 13, 140-151.

Buzai, G. (2020). De Wuhan a Luján. Evolución espacial del COVID-19. Revista Posición, 3. Recuperado de https://www.researchgate.net/publication/340716256

Cuartas, E., Arango-Londoño, D., Guzmán-Escarria, G., Muñoz, E., Caicedo, D., Ortega, D., ... Méndez, F. (2020). Análisis espacio-temporal del SARS-COV-2 en Cali, Colombia. Revista Salud Pública, 22(2), 1-6.

CEPAL. (2002). Vulnerabilidad sociodemográfica: viejos y nuevos riesgos para comunidades, hogares y personas. Brasilia: CEPAL. 
Díaz Caravantes, R. E. (2018). Vulnerabilidad y riesgo como conceptos indisociables para el estudio del impacto del cambio climático en la salud. Región y Sociedad, 30(73), 1-33. https://doi.org/10.22198/rys.2018.73.a968

Espinosa Cancino, C. F., y Cortés Fuentes, A. (2015). Confort higro-térmico en vivienda social y la percepción del habitante. Revista INVI, 85(30), 227-242. https://doi.org/10.4067/S0718-83582015000300008

Esteve et al. (2020). National age and coresidence patterns shape COVID-19 vulnerability. Proceedings of the National Academy of Sciences of the United States of America, 117(28) 16118-16120. https://doi.org/10.1073/pnas.2008764117

Flint, A. (2020). The destiny of density. Recuperado de https://www.lincolninst.edu/publications/articles/2020-06-destiny-density-affordability-equity-effects-of-insidious-virus?fbclid=IwAR34pdGHe4BgqrgUxIzlci4d9Vz0-CpxLKZHm8ojUmcnJwvRmbeLaebo1I

Granados, F. (2020). Las ciudades y el Covid-19: ¿qué hacer? Diario El País, 4 de abril. Recuperado de https://elpais.com/elpais/2020/04/14/opinion/1586821785_782858.html

Hooper, M. (2020). Pandemics and the future of urban density: Michael Hooper on hygiene, public perception and the "urban penalty". Recuperado de https://www.gsd.harvard.edu/2020/04/have-we-embraced-urban-density-to-our-own-peril-michael-hooperon-hygiene-public-perception-and-the-urban-penalty-in-a-global-pandemic/

Huenchuan, S. (2020). COVID-19: Recomendaciones generales para la atención a personas mayores desde una perspectiva de derechos humanos. Recuperado de https://repositorio.cepal.org/bitstream/handle/11362/45316/4/S2000271_es.pdf

Juárez-Ramírez, C., Márquez-Serrano, M., Salgado de Snyder, N., Pelcastre-Villafuerte, B. E., Ruelas-González, M. G., y Reyes-Morales, H. (2014). La desigualdad en salud de grupos vulnerables de México: Adultos mayores, indígenas y migrantes. Revista Panamericana de Salud Pública, 35(4), 284-290. Recuperado de https://scielosp.org/pdf/rpsp/2014.v35n4/284-290/es

Kalabikhina, I. (2020). Demographic and social issues of the pandemic. Population and Economics, 4(2), 103-122. https://doi.org/10.3897/popecon.4.e5389

Lall, S., y Wahba, S. (2020). La construcción de ciudades inclusivas y sostenibles en el período de recuperación de la pandemia no es un mito urbano. Recuperado de https://www.bancomundial.org/es/news/immersive-story/2020/06/18/no-urban-mythbuilding-inclusive-and-sustainable-cities-in-the-pandemic-recovery

Nel·lo, O. (2020). La ciudad y la plaga. eldiario.es, 31 de marzo. Recuperado de https:/www.eldiario.es/tribunaabierta/ciudad-plaga_6_1011808823.html

Perles Roselló, M. J. (2010). Apuntes para la evaluación de la vulnerabilidad social frente al riesgo. Baética, (32), 67-87.

Pickenhayn, J. (2006). Estudio sobre ancianidad: Valioso aporte sobre geografía de la salud en Argentina. Revista Universitaria de Geografia, 15(1), 175-177.

Ramos Ojeda, D. (2019). Entendiendo la vulnerabilidad social: una mirada desde sus principales teóricos. Revista Estudios del Desarrollo Social: Cuba y América Latina, 7(1), 139154. Recuperado de http://scielo.sld.cu/pdf/reds/v7n1/2308-0132-reds-7-01-139.pdf

Santos, J. P. C. dos, Siqueira, A. S. P., Praça, H. L. F., y Albuquerque, H. G. (2020). Vulnerabilidade a formas graves de COVID-19: Uma análise intramunicipal na cidade do Rio de Janeiro, Brasil. Cadernos de Saúde Pública, 36(5), e00075720. https://doi.org/10.1590/0102-311x00075720 
Sortino Barrionuevo, J., y Perles Roselló, M. J. (2017). Metodología para una cartografía de vulnerabilidad del territorio frente al riesgo de inundación relacionado con los sistemas de socorro y asistencia. Aplicación al área inundable del bajo Guadalhorce. Papeles de Geografia, Número monográfico del XV Coloquio Ibérico de Geografía, 157-178. https://doi.org/10.6018/geografia/2017/307051

Suárez Lastra, M., González, C. V., Pérez, M. C. G., Guzmán, L. E. S., Rivera, N. R., Alcántara-Ayala, I., ... Garnica-Peña, R. J. (2020). Índice de vulnerabilidad ante el COVID-19 en México. Investigaciones Geográficas. https://doi.org/10.14350/rig.60140

Subirats, J. (2020). Riscos globals, reptes locals. Les ciutats, més enllà del coronavirus. Dossier "La Ciutat desprès de la pandèmia". Barcelona Metrópolis, 20 de mayo. Recuperado de https://www.barcelona.cat/metropolis/ca/continguts/riscos-globals-reptes-locals-lesciutats-mes-enlla-del-coronavirus

Tamayo, M., Besoaín, Á., y Rebolledo, J. (2018). Determinantes sociales de la salud y discapacidad: Actualizando el modelo de determinación. Gaceta Sanitaria, 32(1), 96-100. https://doi.org/10.1016/j.gaceta.2016.12.004

UNISDR. (2016). Report of the openended intergovernmental expert working group on indicators and terminology relating to disaster risk reduction. United Nations Office for Disaster Risk Reduction. Recuperado de https://www.undrr.org/publication/report-openended-intergovernmental-expert-working-group-indicators-and-terminology

Vidal Gutiérrez, D., Chamblas García, I., Zavala Gutiérrez, M., Müller Gilchrist, R., Rodríguez Torres, M. C., y Chávez Montecino, A. (2014). Social determinants of health and lifestyles in adult population. Concepción, Chile. Ciencia y enfermería, 20(1), 61-74. https://doi.org/10.4067/S0717-95532014000100006 